\title{
Prevalence and Factors Associated with Teenage Pregnancy, Northeast Ethiopia, 2017: A Cross-Sectional Study
}

\author{
Yohannes Ayanaw Habitu ${ }^{\mathbb{D}},{ }^{1}$ Anteneh Yalew, ${ }^{2}$ and Telake Azale Bisetegn ${ }^{3}$ \\ ${ }^{1}$ Department of Reproductive Health, College of Medicine and Health Sciences, University of Gondar, Gondar, Ethiopia \\ ${ }^{2}$ Wogedi District Health Office, Wogedi, South Wollo Zone, Northeast Ethiopia, Ethiopia \\ ${ }^{3}$ Department of Health Communication and Behavioural Sciences, Institute of Public Health, College of Medicine and Health Sciences, \\ University of Gondar, Gondar, Ethiopia
}

Correspondence should be addressed to Yohannes Ayanaw Habitu; yohaneshabitu@gmail.com

Received 21 April 2018; Accepted 24 September 2018; Published 1 November 2018

Academic Editor: Olav Lapaire

Copyright (C) 2018 Yohannes Ayanaw Habitu et al. This is an open access article distributed under the Creative Commons Attribution License, which permits unrestricted use, distribution, and reproduction in any medium, provided the original work is properly cited.

Introduction. Though teen age pregnancy had poor maternal and perinatal health outcomes, its magnitude and determinants are not well understood. Therefore, the aim of this study was to assess the prevalence and associated factors of teenage pregnancy in Wogedi, northeast Ethiopia. Methods. A community-based cross-sectional study was conducted among 514 teenagers in Wogedi, northeast Ethiopia, from April to May 2017. Data were collected using a structured questionnaire, entered, and analyzed appropriately. Odds ratios with 95\% confidence interval and P-values were computed using appropriate logistic regression models to determine the presence and strength of associations between the dependent and independent variables. Results. The prevalence of teenage pregnancy in Wogedi was 28.6\% (95\% CI: 24.9, 32.5). Age (AOR=2.10; 95\% CI: 1.55, 2.88), rural residence (AOR=3.93; 95\% CI: 1.20, 12.83), contraceptive nonuse ( $\mathrm{AOR}=10.62 ; 95 \% \mathrm{CI}: 5.28,21.36)$, and parental marital status (divorce) (AOR=1.98; 95\%CI: 1.13, 3.93) were found to have statistically significant associations with teenage pregnancy. Conclusions. There is high prevalence of teenage pregnancy in the area. Age, residence, contraceptive nonuse, and parental divorce were found to have a statistically significant association. Strengthening contraceptive use by giving special attention to rural dwellers and showing the consequences of divorce to the community are strongly recommended.

\section{Introduction}

Adolescent pregnancy is defined as a pregnancy in girls 10-19 years of age. It is estimated that about 16 million girls $15-19$ years old give birth each year, contributing nearly $11 \%$ of all births worldwide [1]. Although adolescent fertility rates are falling globally, approximately 18 million girls under the age of 20 give birth each year [2]. Two million of these births are from girls under 15 years of age [2]. More than $90 \%$ of these births occur in low and middle-income countries [1-3]. Most teenage pregnancies and childbirths take place in west and central Africa, east and southern Africa, South Asia, Latin America, and the Caribbeans [2].

Different pieces of literature show that the prevalence of teenage pregnancy varies across regions of the world. In the Asia Pacific regions, it ranges up to $43 \%$ in Bangladesh [4] and from $11.1 \%$ [5] to $47.3 \%$ in Nepal [6]. In Jordan, the prevalence is $25 \%$ [7]. The prevalence of teenage pregnancy also varies in Africa; for instance, in Nigeria, it ranges from $6.2 \%$ in Niger Delta state [8] to 49\% in Abia State [9]. In South Africa [10], East Africa (Kenya) [11], Assossa (Ethiopia) [12], and Sudan [13], it ranges from 2.3 to $19.2 \%, 31 \%, 20.4 \%$, and $31 \%$, respectively.

Currently about $17 \%$ of the adolescents between 15 and 19 years in Ethiopia are married [14] and the median age of women at first sexual intercourse is now 16.6 years [14]. There is a low contraceptive prevalence rate (CPR) $(7.5 \%)$ among all female adolescents of 15-19 years; CPR is higher among currently married $(31.9 \%)$ and sexually active unmarried adolescents (59\%) of the same age [14]. In addition, $20.5 \%$ of female adolescents 15-19 years face unmet needs for family planning and 52.5\% total demand for same [14].

Teenage pregnancy is very common in Ethiopia, and it is an important demographic factor making the country the 
second most populous in Africa, with a total population of around 102 million in 2016 [15]. According to the EDHS 2016 finding, the prevalence of teenage pregnancy is $13 \%$ [14]. It varies depending on residence, urban 5\%, and rural 15\% [14]. Moreover, disparities are seen across regions, with the highest $23 \%$ in Afar, $8 \%$ in Amhara, and the lowest 3\% in Addis Ababa [14].

Literature showed different sociodemographic, cultural, and other individual factors were associated with teenage pregnancy. Approximately $90 \%$ of teenage pregnancies in the developing world are of girls who are married, owing to their high exposure to sex and pressure to conceive quickly after marriage $[8,16-18]$. As a result, the majority $(75 \%)$ of married teenage pregnancies are planned $[1,17]$. Employment status $[6,9,18,19]$, poverty $[2,6,14,20-22]$, marital status $[9,12,18,23]$, type of occupation $[12,21]$, culture $[9,11]$, peer pressure [11, 20,22, 24], early marriage [25], forced marriage [20], rape [26], and the need for a dowry [20] were factors associated with teenage pregnancy in recorded literature.

Studies have shown that teenage pregnancy has poor maternal and perinatal health outcomes $[1,2,8,27]$. Complications during pregnancy and childbirth are the second cause of death for 15-19-year-old girls globally [1]. Every year, some 3 million girls aged 15 to 19 undergo unsafe abortions [1]. Babies born to adolescent mothers face a substantially high risk of dying than those born to women aged 20 to $24[1,25]$. School dropout $[14,20,22,25]$, poverty $[2,25]$, high rate of marriage [8], pregnancy-induced hypertension [27-30], and induced abortion $[1,20]$ are some of the consequences of adolescent pregnancy on the mother. Preterm delivery $[19,27$, 29-31], low birth weight [5, 19, 27, 29-32], stillbirth [5, 27, 31], and high fetal and neonatal mortality $[19,27,29,30,32]$ are some of the consequences of teenage pregnancy for the fetus.

The limited studies conducted in the world as well as in Ethiopia have tried to show the prevalence and factors associated with teenage pregnancy, but most of the studies were done using secondary data (health facility-based studies). Hence, due to the poor data recording system of our country, we may not get appropriate information from health facilities. Moreover, research results from health facilities lack representativeness to the general population. Therefore, this study was conducted to show the prevalence and determinants of teenage pregnancy in Wegedi, northeast Ethiopia, 2017, by using primary data.

\section{Materials and Methods}

2.1. Study Design and Setting. This community-based crosssectional study was conducted in Wogedi from April to May 2017. Wogedi, one of the districts in South Wollo zone, is $192 \mathrm{~km}$ to the west of Dessie. According to the national census report of 2007, the projected population of Wogedi for the year 2016 was 152,719 of whom $26.5 \%$ were adolescents 15-19 years of age [33]. Wogedi has 35 kebeles (lowest administrative units), two district health offices, five health centers, and thirty-two health posts [33].

2.2. Source and Study Population. All female adolescents 1519 years of age in the selected kebeles of Wogedi were the source population of the study.

\subsection{Inclusion Criteria. Female adolescents $15-19$ years of age.}

2.4. Sample Size and Sampling Procedure. The sample size was calculated using the single population proportion formula with the following assumptions. The proportion of teenage pregnancy among 15-19 years of age females in Ethiopia (20.4\%) [34] was taken from the previous study with a $5 \%$ margin of error and 95\% confidence interval. Lastly, by considering a $10 \%$ nonresponse rate, and a design effect of 2, the final sample size obtained was 542. A multistage sampling technique was employed in order to select study units. First, out of the 35 kebeles, six were selected randomly, to represent $20 \%$ of the district population. Then, to each selected kebele, we allocated the sample size by considering the proportional allocation technique. Finally, study units were randomly selected at the household level using the lottery method.

\subsection{Study Variables}

\subsubsection{Dependent Variable. Teenage pregnancy.}

2.5.2. Independent Variables. Sociodemographic variables, like age, sex, marital status, education, occupation, and income were considered. History of sexual and reproductive health, like age at first sexual intercourse, early marriage, contraceptive use, perception on teenage pregnancy, family income, family education, peer pressure, and casual sex assessed.

2.6. Operational Definition. Teenage pregnancy: pregnancy in adolescents 15-19 years who believe that they are pregnant and confirmed by a health care providers.

2.7. Data Collection Instruments and Procedures. Data were collected using a pretested, structured, intervieweradministered questionnaire which was first prepared in English and translated into Amharic (the local language) by a language expert. Then, the Amharic version was again translated back to English to check for consistency. The structured, interviewer-administered questionnaire was adapted from the WHO (Illustrative-questionnaire for interview survey with young people developed by John Cleland) standard tool which was developed to assess the sexual and reproductive health of adolescents and youth. Appropriate modifications were made to fit with the local set up. In addition we conducted a pretest and we have made some simple analysis to see if we can address the desired objectives or not, from the results of the pretest. Moreover, some language corrections and rearrangements on the order of questions were made to keep the logical flow of the questions, based on the comments from the pretest we got. Four data collectors, with Bachelor's degrees in nursing and data collection experience were recruited. One supervisor, with a master's of public health was employed. The supervisor and data collectors were females chosen in order to minimize participant discomfort. A one day training was given to data collectors and the supervisor to help them know the objective and the relevance of the study and the rights of the respondents either to participate or decline. 
2.8. Data Management. Data manually checked by the investigators were entered and cleaned using EPI info data version 7 and exported to SPSS version 20 for further analysis. Descriptive statistics like frequencies, percentages, and means were computed. Bivariable analyses were carried out to examine the relationship between teenage pregnancy and each explanatory variable. All explanatory variables that were statistically significant at the Bivariable model at $<0.2 p$-value were included in the multivariate logistic regression model to see the real determinants of teenage pregnancy. Adjusted odds ratios with a $95 \%$ confidence interval were computed, and variables with a p-value $<0.05$ in the Multivariate Model were considered as statistically significant.

2.9. Ethical Considerations. Ethical approval was obtained from the Institutional Review Board (IRB) of the Institute of Public Health, College of Medicine and Health Sciences, the University of Gondar (IRB reference number: IPH/2471/2017). Participants were informed about the objective of the study and the fact that the confidentiality of their responses will be insured by excluding personal identifiers and carefully securing the questionnaire in such a way that it is accessed only by the investigators.

\section{Results}

3.1. Sociodemographic Characteristics of Respondents. A total of 514 female adolescents 15-19 years of age were included in the study with a response rate of $95 \%$. The majority, 157 (30.5\%), of the respondents were 19 years old, with the median Inter Quartile Range of 3 years. More than half, 270 (52.5\%), of the respondents were Orthodox Christians. Three hundred seventeen, (61.7\%), attended primary school, and more than half, 271 (52.7\%), were married. Nearly half, 253 (49.2\%), of the respondents were students, and 251 (48.8\%) earned less than Birr 1500 per month (Table 1).

3.2. Sexual and Reproductive Health Characteristics of Participants. This study showed that $337(65.6 \%)$ of the respondents had sexual intercourse and that $130(38.6 \%)$ started it before 15 years of age. Out of those who had sex, 156 (46.3\%), used contraceptives. The proportion of teenage pregnancy among respondents in Wogedi was 147 (28.6\%) with a 95\% CI $(24.9,32.5)$. The study also indicated that the majority of the pregnancies, 93 (63.3\%), were unplanned, and $54(36.7 \%)$ of the teenagers were unhappy about their pregnancy. Moreover, $36(24.5 \%)$ were pregnant at the time of the survey (Table 2).

The major reason mentioned by $65 \%$ of the respondents for exposure to pregnancy was marriage, followed by $20 \%$ who were exposed for nonuse of contraceptives.

3.3. Factors Associated with Teenage Pregnancy. Age, religion, educational status, marital status, occupation, living arrangement, parent's age, parents' religion, parents' marital status, parents' monthly income, and contraceptive nonuse were variables with P-values of less than 0.2 in the Bivariable Logistic regression. All variables with less than $0.2 \mathrm{P}$-values were fitted in to the multivariate logistic regression model
TABLE 1: Sociodemographic characteristics of teenagers in Wogedi, northeast Ethiopia, 2017.

\begin{tabular}{|c|c|c|}
\hline Variables & Frequency $(\mathrm{N}=514)$ & Percent \\
\hline \multicolumn{3}{|l|}{ Age in years } \\
\hline 15 & 86 & 16.7 \\
\hline 16 & 83 & 16.2 \\
\hline 17 & 76 & 14.8 \\
\hline 18 & 112 & 21.8 \\
\hline 19 & 157 & 30.5 \\
\hline \multicolumn{3}{|l|}{ Religion } \\
\hline Muslim & 244 & 47.5 \\
\hline Orthodox & 270 & 52.5 \\
\hline \multicolumn{3}{|l|}{ Marital status } \\
\hline Married & 205 & 39.9 \\
\hline Divorced & 63 & 12.3 \\
\hline Widowed & 3 & 0.6 \\
\hline Single & 243 & 47.2 \\
\hline \multicolumn{3}{|l|}{ Educational status } \\
\hline College & 5 & 1.0 \\
\hline Secondary (9-12) & 101 & 19.6 \\
\hline Primary (1-8) & 317 & 61.7 \\
\hline Unable to read and write & 91 & 17.7 \\
\hline \multicolumn{3}{|l|}{ Occupation } \\
\hline Farmer & 173 & 33.7 \\
\hline Housewife & 39 & 7.6 \\
\hline Merchant & 18 & 3.5 \\
\hline Daily laborer & 31 & 6.0 \\
\hline Student & 253 & 49.2 \\
\hline \multicolumn{3}{|l|}{ Live with } \\
\hline Alone & 16 & 3.1 \\
\hline Husband & 164 & 31.9 \\
\hline Parent & 334 & 65.0 \\
\hline \multicolumn{3}{|l|}{ Expected household income } \\
\hline$<1500$ & 251 & 48.8 \\
\hline $1501-7500$ & 244 & 47.5 \\
\hline$>7500$ & 19 & 3.7 \\
\hline
\end{tabular}

after adjusting for possible confounders. In the multivariate logistic regression model, age, residence, contraceptive nonuse, and parents' marital status were identified as statistically significant variables.

Increase in age is significantly associated with teenage pregnancy (AOR=2.10; CI: 1.55, 2.88). Teenagers from rural settings were more likely to be pregnant than students (AOR=3.93; 95\% CI: 1.20, 12.83). This study also showed that contraceptive nonuse was found to be significantly associated with teenage pregnancy. Respondents who did not use contraceptives were ten times ( $\mathrm{AOR}=10.62$; 95\%CI: 5.28, 21.36) more likely to be pregnant than their counterparts.

Teenagers from divorced parents were nearly two times more exposed to teenage pregnancy as compared to those who were from married parents (AOR $=1.98$; 95\%CI: 1.13 , 3.93) (Table 3). 
TABLE 2: Sexual and reproductive health characteristics of teenagers in Wogedi, northeast Ethiopia, 2017.

\begin{tabular}{|c|c|c|}
\hline Variable & Frequency & Percent \\
\hline \multicolumn{3}{|l|}{ Ever had sex $(\mathrm{N}=514)$} \\
\hline No & 177 & 34.4 \\
\hline Yes & 337 & 65.6 \\
\hline \multicolumn{3}{|l|}{ Age at first sex $(\mathrm{N}=337)$} \\
\hline $13-15$ & 130 & 38.6 \\
\hline $16-18$ & 205 & 60.8 \\
\hline$>18$ & 2 & 0.6 \\
\hline \multicolumn{3}{|l|}{ Contraceptive use $(\mathrm{N}=337)$} \\
\hline No & 181 & 53.7 \\
\hline Yes & 156 & 46.3 \\
\hline \multicolumn{3}{|c|}{ Reasons for contraceptive non-use $(\mathrm{N}=181)$} \\
\hline Do not have accesses & 17 & 9.4 \\
\hline Do not have knowledge & 68 & 37.6 \\
\hline Family influence & 81 & 44.8 \\
\hline Due to divorce & 8 & 4.4 \\
\hline Wants to be pregnant & 7 & 3.8 \\
\hline \multicolumn{3}{|l|}{ Ever had pregnancy $(\mathrm{N}=514)$} \\
\hline No & 367 & 71.4 \\
\hline Yes & 147 & 28.6 \\
\hline \multicolumn{3}{|c|}{ Currently pregnant $(\mathrm{N}=147)$} \\
\hline No & 111 & 75.5 \\
\hline Yes & 36 & 24.5 \\
\hline \multicolumn{3}{|c|}{ Conditions of pregnancy $(\mathrm{N}=147)$} \\
\hline Planned & 54 & 36.7 \\
\hline Unplanned & 93 & 63.3 \\
\hline \multicolumn{3}{|c|}{ Feeling about the pregnancy $(\mathrm{N}=147)$} \\
\hline Happy & 58 & 39.5 \\
\hline Unhappy & 64 & 43.5 \\
\hline Nothing & 25 & 17.0 \\
\hline \multicolumn{3}{|c|}{ Outcomes of pregnancy $(\mathrm{N}=111)$} \\
\hline Delivered (Live Birth) & 97 & 87.4 \\
\hline Aborted & 14 & 12.6 \\
\hline
\end{tabular}

\section{Discussion}

The prevalence of teenage pregnancy extremely varies in the world. Some of the reasons for these differences could be variations in sociodemographic, cultural, sexual, and reproductive health characteristics of adolescents. This study explored the prevalence of teenage pregnancy and its associated factors in Wogedi district, northeast Ethiopia. The study showed that the prevalence of teenage pregnancy was $28.6 \%$ (95\% CI: 24.9, 32.5). Factors associated with it were increase in age, farming occupation, contraceptive nonuse, and parents' marital status (divorce).

This finding is similar with those of studies conducted in Sudan, 31\% [13], Kenya, 31\% [11], Jordan, 25\% [7], and Turkey, $29 \%$ [35]. This similarity could be due to the presence of some related sociodemographic, cultural, and individual adolescent characteristics in the current and those studies. For instance, the proportion of married adolescents in the Kenya study was similar to that of the current study. Moreover, there was a similarity in the culture of early marriage in the current and the other studies.

This finding is higher than the $13.0 \%$ national report on teenage pregnancy [14]. The possible reason may be that the EDHS study includes all settlements, like urban and rural areas, whereas the current study was conducted in one of the rural districts in Amhara Region, where there is a high prevalence of early marriage. In the region, the median age at first marriage is 16.2 years, and the median age at first sex 15.8 years, the lowest in the country [14]. All these factors may contribute to the high prevalence of teenage pregnancy in the current study as compared to the national one.

This finding is higher than those of studies conducted in Niger Delta state of Nigeria 6.2\% [8], and Assosa 20.4\% [12]. The variation could be due to the presence of some sociodemographic, cultural, sexual, and reproductive characteristics of participants in the other and the current study. For instance, the proportion of marriage in the Niger Delta state was $27.7 \%$ [8], lower than that of the current study $39.9 \%$. Shreds of evidence showed that as the proportion of marriage increased, the probability of exposure to pregnancy also increased [36]. In addition, the proportion of participants who had secondary or more education was higher in the Niger Delta state study (46.0\%) [8] compared to the current study (20.6\%). Evidence showed that as the educational level of girls increased, the chance of exposure to pregnancy decreased [14]. Compared to marriage in the current study (39.9\%), the proportion of marriage was lower in the Assosa study 20.7\% [12]. In addition, the proportion of participants who could not read and write was lower in the Assosa study (3.4\%) [12] compared to that of the current study $(17.7 \%)$. Moreover, the proportion of contraceptive use was higher (69.5\%) in the Assosa study [12] compared to the present study (46.3\%). Different scientific researchers showed contraceptive use decreased the prevalence of teenage pregnancy [36].

This finding is lower than those of studies conducted in Abia State of Nigeria (49.0\%) [9] and the Cape Coast Municipality in Nepal (47.3\%) [6]. This difference could be due to some social, cultural, and individual characteristics of participants and the time gap among the studies. For instance, in the Abia study, the proportion of participants who had no formal education (28.5\%) [9] was more than that of the current study which represented $17.7 \%$. Moreover, the proportion of study participants who were unemployed (75.8\%) was higher in Abia State study [9] compared to that of the present study (49.2\%). The possible explanation for these may be unemployed adolescents may have poorer access to contraceptives; hence, the chance of getting pregnancy increased. In the study conducted in Cape Coast Municipality, Nepal, the proportion of participants who had no formal education (30.2\%) [6], was higher compared to that of the current study (17.7\%). Furthermore, the proportion of participants who had secondary education and above $(2.1 \%)$ [6] was less in the Nepal study compared to that of the present study $(20.6 \%)$. Besides, the proportion of contraceptive use in the Nepal study $11.1 \%$ [6] was less than that of the present study $(53.7 \%)$. 
TABLE 3: Bivariable and multivariable logistic regression analysis showing factors associated with teenage pregnancy in Wogedi, northeast Ethiopia, 2017.

\begin{tabular}{|c|c|c|c|c|}
\hline \multirow{2}{*}{ Variable } & \multicolumn{2}{|c|}{ Teenage pregnancy } & \multirow{2}{*}{ Crude OR (95\% CI) } & \multirow{2}{*}{ Adjusted OR (95\% CI) } \\
\hline & Yes & No & & \\
\hline Age $($ Mean $=17.33$ years with $\mathrm{SD}=1.47)$ & 147 & 367 & $2.60(2.12,3.20)$ & $2.10(1.55,2.88) * *$ \\
\hline \multicolumn{5}{|l|}{ Marital status } \\
\hline Married & 111 & 94 & $30.7(14.9,41.0)$ & $2.16(0.59,4.80)$ \\
\hline Divorced & 24 & 39 & $16.0(6.9,36.1)$ & $1.38(0.37,5.00)$ \\
\hline Widowed & 3 & 0 & - & - \\
\hline Single & 9 & 234 & 1 & 1 \\
\hline \multicolumn{5}{|l|}{ Educational level } \\
\hline College & 2 & 3 & $0.5(0.08,3.13)$ & $3.00(0.28,6.1)$ \\
\hline Secondary & 4 & 97 & $0.03(0.01,0.09)$ & $0.87(0.42,1.78)$ \\
\hline Primary & 89 & 228 & $0.29(0.18,0.47)$ & $0.41(0.10,1.67)$ \\
\hline Unable to read and write & 52 & 39 & 1 & 1 \\
\hline \multicolumn{5}{|l|}{ Occupation } \\
\hline Farmer & 91 & 82 & $30.00(14.5,62.3)$ & $3.93(1.20,12.83) *$ \\
\hline House wife & 28 & 11 & $69.01(26.3,80.0)$ & $4.23(0.94,19.01)$ \\
\hline Merchant & 12 & 6 & $54.22(16.5,77.0)$ & $4.26(0.75,6.13)$ \\
\hline Daily laborer & 7 & 24 & $7.91(2.73,23.1)$ & $1.42(0.31,6.57)$ \\
\hline Student & 9 & 244 & 1 & 1 \\
\hline \multicolumn{5}{|l|}{ Live with } \\
\hline Alone & 11 & 5 & $16.62(5.43,20.04)$ & $3.24(0.55,8.83)$ \\
\hline Husband & 97 & 67 & $10.91(6.93,17.01)$ & $2.26(0.81,6.28)$ \\
\hline Parents & 39 & 295 & 1 & 1 \\
\hline \multicolumn{5}{|l|}{ Monthly income } \\
\hline$<1500$ & 81 & 170 & $0.65(0.25,1.69)$ & $2.59(0.69,9.61)$ \\
\hline $1501-7500$ & 58 & 186 & $0.42(0.16,1.12)$ & $1.33(0.36,4.96)$ \\
\hline$>7500$ & 8 & 11 & 1 & 1 \\
\hline \multicolumn{5}{|l|}{ Parent age } \\
\hline $30-49$ & 95 & 265 & $0.7(0.46,1.04)$ & $0.96(0.49,1.86)$ \\
\hline$>49$ & 52 & 102 & 1 & 1 \\
\hline \multicolumn{5}{|l|}{ Parents' marital status } \\
\hline Divorced & 7 & 29 & $2.2(0.72,6.90)$ & $1.98(1.13,3.93) *$ \\
\hline Widowed & 14 & 36 & $2.42(0.91,6.32)$ & $1.54(0.12,18.95)$ \\
\hline Married & 126 & 302 & 1 & 1 \\
\hline \multicolumn{5}{|l|}{ Contraceptive use } \\
\hline No & 117 & 64 & $7.6(4.65,12.67)$ & $10.62(5.28,21.36) * *$ \\
\hline Yes & 30 & 126 & 1 & 1 \\
\hline
\end{tabular}

$*$ Significant at a p-value less than 0.05 and $* *$ significant at a p-value less than 0.001 ; SD: Standard Deviation.

In this study, as respondents' age increased by one year, the odds of being pregnant increased by $2.1 \%$. This finding is in line with that of national study in Ethiopia [14], Kenya [11], and Abia State [9]. As age increases, teenagers will have more exposure to sex and their chance of being married will also increase to procreate children.

Teenagers from rural setups were four times more likely to have pregnancy compared to student respondents. This finding is consistent with that of a study conducted in South Asia [37]. This might be so because teenagers from the rural areas are less educated and have limited access to contraceptives. Besides, rural communities are pronatalists compared to educated people [14].
Contraceptive nonusers were nearly eleven times more likely to be pregnant compared to those who used contraceptives. Other studies are in line with this finding in that the prevalence of teenage pregnancy increased among contraceptive nonusers $[18,20,36]$. It has been evidenced that as the proportion of contraceptive nonusers increased the proportion of pregnancy increased [36].

Teenagers from divorced parents were nearly two times more exposed to teenage pregnancy compared to adolescents from married parents (AOR=1.98; 95\%CI: 1.13, 3.93). This is due to the existence of low parental control and communication about sexual and reproductive issues among divorced parents compared to married ones. These lead 
to increased early sexual debut and risky sexual behaviors among adolescents from divorced parents, and all these expose them to teenage pregnancy [38-40]. Since the study design employed is a cross-sectional, causality may not be inferred. Social desirability bias is one of the potential biases, which may affect the results of this study. To minimize the effect of social desirability bias we recruited data collectors who have no close contact with the respondents.

\section{Conclusions}

This study showed that there is a high prevalence of teenage pregnancy in the area. Increased age, rural residence, contraceptive nonuse, and parental marital status (divorce) were found to have a statistically significant association with teenage pregnancy. Strengthening contraceptive service promotion and provision for teenagers by giving special attention to rural ones and showing the consequences of divorce in the community are strongly recommended.

\section{Abbreviations}

AOR: Adjusted odds ratio

CI: Confidence interval

COR: Crude Odds Ratio

CPR: Contraceptive prevalence rate

EDHS: Ethiopian Demographic Health Survey

SPSS: Statistical Package for Social Science.

\section{Data Availability}

The data used to support the findings of this study are included with in the article.

\section{Disclosure}

Anteneh Yalew is Principal Investigator.

\section{Conflicts of Interest}

The authors declare that they have no conflicts of interest in this work.

\section{Authors' Contributions}

Yohannes Ayanaw Habitu, Anteneh Yalew, and Telake Azale Bisetegn were involved in study conception, design, coordination, data collection, data analysis, interpretation, and write-up. Yohannes Ayanaw Habitu prepared the manuscript. All authors read and approved the final manuscript.

\section{Acknowledgments}

The authors would like to acknowledge all the study participants for participation in the study, the data collectors, supervisors, and authorities of Wogedi district, University of Gondar, and Institute of Public Health for ethical approval.

\section{References}

[1] WHO, "Adolescent pregnancy fact sheet," 2014.

[2] UNFPA, "Motherhood in Childhood, Facing the challenge of adolescent pregnancy, state of world population," 2013.

[3] WHO, Guidelines on Preventing Early Pregnancy and Poor Reproductive Outcome Among Adolescents in Developing Countries, WHO, Geneva, 2011.

[4] E. Presler-Marshall and N. Jones, "Charting the future, Empowering girls to prevent early pregnancy," 2012.

[5] L. Lama, P. Rijal, S. Budathoki, and A. D. Shrestha, "Profile of neonates born to adolescent mothers at Nepal," Nepal Medical College journal, vol. 14, no. 4, pp. 294-297, 2012.

[6] F. Dagadu, The Magnitude and Determinants of Teenage Pregnancy in the Cape Coast Municipality, University of Ghana, Accra, Ghana, 1997.

[7] S. Ziadeh, "Obstetric outcome of teenage pregnancies in north Jordan," Archives of Gynecology and Obstetrics, vol. 265, no. 1, pp. 26-29, 2001.

[8] O. Ayuba Gani, "Outcome of teenage pregnancy in the Niger Delta of Nigeria," Ethiopian journal of health sciences, vol. 22, no. 1, pp. 45-50, 2012.

[9] U. M. Nwosu, "Contemporary factors of teenage pregnancy in rural communities of Abia state, Nigeria," International Journal Of Community Medicine And Public Health, vol. 4, no. 2, pp. 588-592, 2017.

[10] G. Mchunu, K. Peltzer, B. Tutshana, and L. Seutlwadi, "Adolescent pregnancy and associated factors in South Africa," African health science, vol. 12, no. 4, pp. 426-434, 2012.

[11] M. Were, "Determinants of teenage pregnancies: The case of Busia District in Kenya," Economics \& Human Biology, vol. 5, no. 2, pp. 322-339, 2007.

[12] B. Assefa, M. Abiyou, and G. Yeneneh, "Assessment of the magnitude of teenage pregnancy and its associated factors among teenage females visiting Assosa General Hospital," Ethiopian Medical Journal, vol. 53, p. 53, 2015.

[13] G. K. Adam, E. M. Elhassan, A. M. Ahmed, and I. Adam, "Maternal and perinatal outcome in teenage pregnancies in Sudan," International Journal of Gynecology and Obstetrics, vol. 105, no. 2, pp. 170-171, 2009.

[14] Central Statistical Agency and The DHS Program ICF, The DHS Program ICF Rockville M, USA Ethiopian Demographic and Health Survey, vol. 201, CSA and ICF, Addis Ababa, Ethiopia and Rockville, MD, USA, 2017.

[15] Agency CI, "The World Fact Book, Country population Comparison," 2016.

[16] A. Erulkar, "Adolescence lost: The realities of child marriage," Journal of Adolescent Health, vol. 52, no. 5, pp. 513-514, 2013.

[17] E. Presler-Marshal and N. Jones, Charting The Future: Empowering Girls to Prevent Early Pregnancy, ODI and save the children, London, UK, 2012.

[18] T. Alemayehu, J. Haider, and D. Habte, "Determinants of adolescent fertility in Ethiopia," Ethiopian Journal of Health Development, vol. 24, no. 1, pp. 30-38, 2010.

[19] H. U. Ezegwui, L. C. Ikeako, and F. Ogbuefi, "Obstetric outcome of teenage pregnancies at a tertiary hospital in Enugu, Nigeria," Nigerian Journal of Clinical Practice, vol. 15, no. 2, pp. 147-150, 2012.

[20] G. Vincent and F. M. Alemu, "Factors contributing to, and effects of, teenage pregnancy in Juba," South Sudan Medical Journal, vol. 9, no. 2, pp. 28-31, 2016. 
[21] O. E. Amoran, "A comparative analysis of predictors of teenage pregnancy and its prevention in a rural town in Western Nigeria.", International Journal for Equity in Health, vol. 11, article no. 37, 2012.

[22] C. Gyan, "The effects of teenage pregnancy on the educational attainment of girls at Chorkor, a suburb of Accra," Journal of Educational and Social Research, vol. 3, no. 3, p. 53, 2013.

[23] R. Gideon, "Factors Associated with Adolescent Pregnancy and Fertility in Uganda: Analysis of the 2011 Demographic and Health Survey Data," The Social Science Journal, vol. 2, no. 1, p. 7, 2013.

[24] K. Mwaba, "Perceptions of teenage pregnancy among South African adolescents," Health SA Gesondheid, vol. 5, no. 3, pp. 30-34, 2000.

[25] E. Presler-Marshall and N. Jones, "Charting the future: Empowering girls to prevent early pregnancy," 2012.

[26] A. de Haan, "Teenage Pregnancy and Motherhood in Merkato Slums in Ethiopia: Perspectives of Teenagers and Implications for Sexual," 2010.

[27] G. Qazi, "Obstetric characteristics and complications of teenage pregnancy," Journal of Postgraduate Medical Institute, vol. 25, no. 2, pp. 134-138, 2011.

[28] I. Goonewardene and R. Waduge, "Adverse effects of teenage pregnancy," Ceylon Medical Journal, vol. 50, no. 3, 2009.

[29] T. Ganchimeg, E. Ota, N. Morisaki et al., "Pregnancy and childbirth outcomes among adolescent mothers: a World Health Organization multicountry study," BJOG: An International Journal of Obstetrics and Gynaecology, vol. 121, pp. 40-48, 2014.

[30] A. Kumar, T. Singh, S. Basu, S. Pandey, and V. Bhargava, "Outcome of teenage pregnancy," The Indian Journal of Pediatrics, vol. 74, no. 10, pp. 927-931, 2007.

[31] E. Kovavisarach, S. Chairaj, K. Tosang, S. Asavapiriyanont, and U. Chotigeat, "Outcome of teenage pregnancy in Rajavithi Hospital," Journal of the Medical Association of Thailand, vol. 93, no. 1, pp. 1-8, 2010.

[32] G. Woldemichael, "Teenage Childbearing and its Health Consequences on the Mother and Child in Eritrea," Journal of the Eritrean Medical Association, vol. 1, no. 1, 2010.

[33] office Wwfaed, "Socio-demographic profile of wogedi woreda for the year 2016/2017," 2017.

[34] B. Assefa, "Assessment of the magnitude of teenage pregnancy and its associated factors among teenage females," Ethiopian Medical Journal, 2015.

[35] S. Canbaz, A. T. Sunter, C. E. Cetinoglu, and Y. Peksen, "Obstetric outcomes of adolescent pregnancies in Turkey," Advances in Therapy, vol. 22, no. 6, pp. 636-641, 2005.

[36] J. Bongaarts, "The fertility-inhibiting effects of the intermediate fertility variables.," Studies in Family Planning, vol. 13, no. 6-7, pp. 179-189, 1982.

[37] D. R. Acharya, R. Bhattarai, and A. Poobalan, "Factors associated with teenage pregnancy in South Asia," 2014.

[38] R. D. Day, "The Transition to First Intercourse among Racially and Culturally Diverse Youth," Journal of Marriage and Family, vol. 54, no. 4, p. 749, 1992.

[39] B. J. Ellis, J. E. Bates, K. A. Dodge et al., "Does Father Absence Place Daughters at Special Risk for Early Sexual Activity and Teenage Pregnancy?" Child Development, vol. 74, no. 3, pp. 801821, 2003.

[40] R. L. Flewelling and K. E. Bauman, "Family Structure as a Predictor of Initial Substance Use and Sexual Intercourse in Early Adolescence," Journal of Marriage and Family, vol. 52, no. 1, p. 171, 1990. 


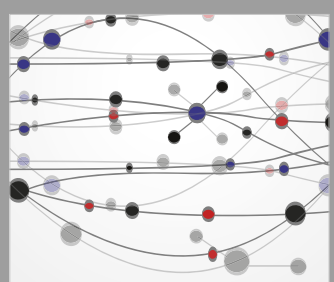

The Scientific World Journal
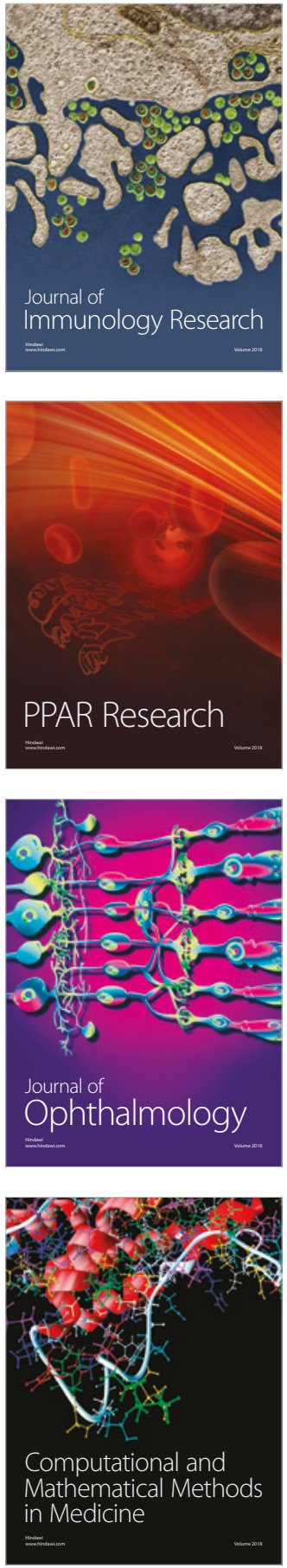

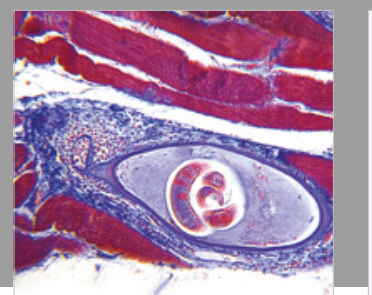

Gastroenterology Research and Practice

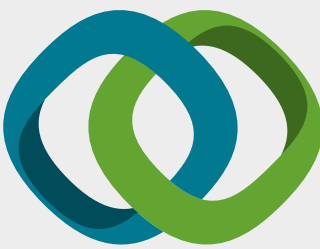

\section{Hindawi}

Submit your manuscripts at

www.hindawi.com
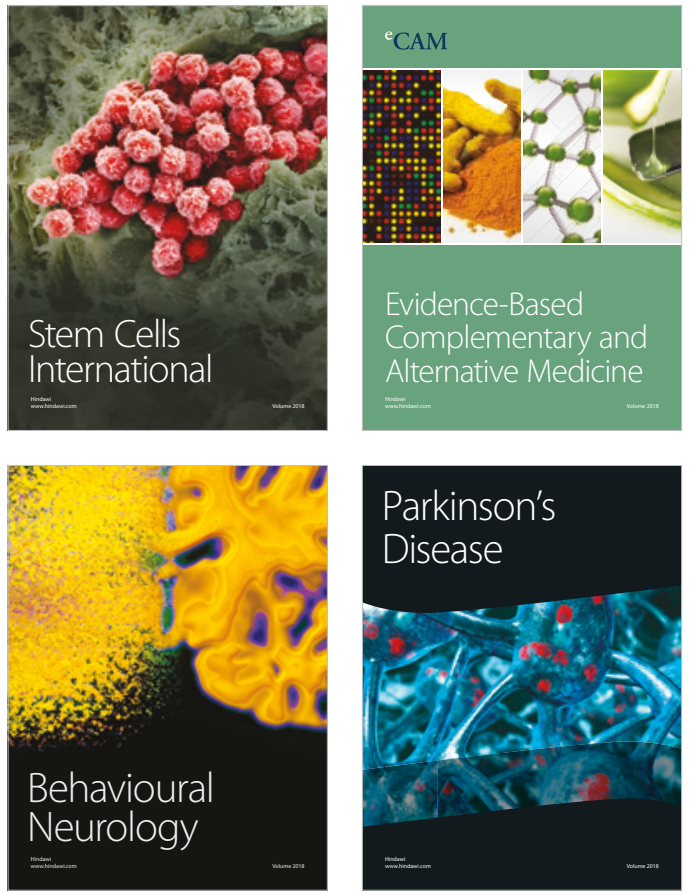

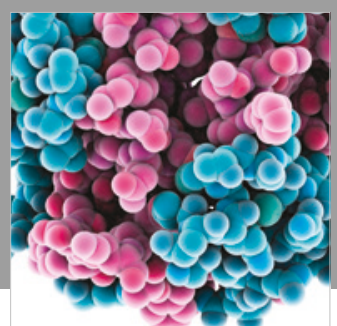

ournal of

Diabetes Research

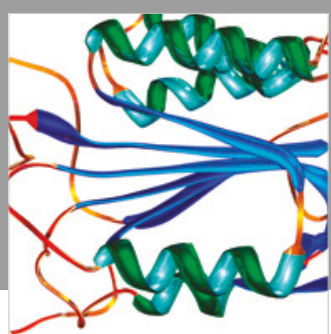

Disease Markers
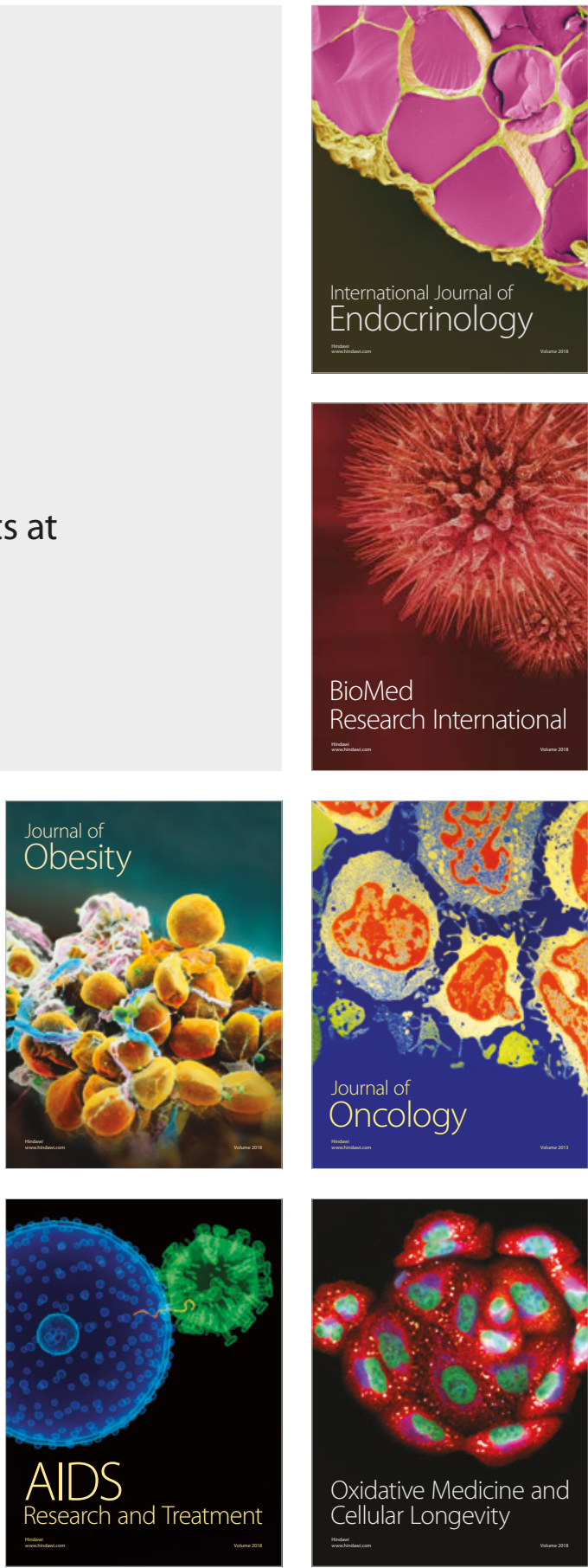